\title{
Functional abilities at age 4 years of children born before 29 weeks of gestation
}

\author{
Ann Johnson, Pat Townshend, Patricia Yudkin, Diana Bull, Andrew R Wilkinson
}

\begin{abstract}
Objectives-To assess the rate of impairment and disability among babies born very preterm and to investigate the association between such impairment and gestational age at birth.

Design-Cohort study of a geographically defined population of babies.

Setting-Oxford Regional Health Authority.

Subjects-All babies born alive before 29 weeks of gestation to mothers resident in the region during 1984-6.

Main outcome measures-Survival rates and rates of impairment and disability among survivors at the age of 4 years.

Results-Of the 342 babies, half (170) survived to be discharged home. Of the 164 survivors to age 4 years, $153(93 \%)$ were assessed. A total of 35 (23\%; $95 \%$ confidence interval $16 \%$ to $30 \%$ ) were severely disabled and only 54 (35\%; $28 \%$ to $43 \%$ ) were unimpaired. The risk of impairment and disability increased with decreasing gestational age at birth $(\mathbf{p}<0.003)$.

Conclusions-With the increasing survival rate among babies born before 29 weeks of gestation, we need urgently to establish reliable ways of monitoring the proportion of survivors who have a disability.
\end{abstract}

National Perinatal

Epidemiology Unit, Radcliffe Infirmary, Oxford OX2 6HE

Ann Johnson, paediatrician Pat Townshend, research nurse

University Department of Paediatrics, John Radcliffe Hospital, Oxford OX3 9DU Andrew R Wilkinson, reader and consultant paediatrician

Nuffield Department of

Obstetrics and

Gynaecology, John

Radcliffe Hospital, Oxford

OX3 9DU

Patricia Yudkin, statistician

Cancer Epidemiology Unit, Radcliffe Infirmary, Oxford OX2 6HE

Diana Bull, research officer

Cancer Epidemiology Unit, Radclifie Infirmary, Oxford OX2 6HE

Diana Bull, research officer

Correspondence to: Ann Johnson.

BMF 1993;306:1715-8

\section{Introduction}

It has been recognised for some years that babies born very preterm who survive to go home from the neonatal intensive care nursery are at greater risk of later impairment and disability than babies who are born at term. ${ }^{\prime}$ Through the 1980 s there was an increase in the rate of survival among babies of very low birth weight $^{2}$ or who were born very preterm. ${ }^{3}$ This was attributed to the development of new techniques and interventions in neonatal intensive care. The number of impaired and disabled survivors may also have increased. The increase in the number of preterm babies who later develop cerebral palsy, reported by those who hold population based registers for cerebral palsy, ${ }^{45}$ would seem to support this concern.

The increase in survival has occurred particularly among babies born before 29 weeks of gestation, ${ }^{6}$ and survival as early as 23 and 24 weeks is now more common. There is a clear association between gestational age at birth and survival, and a stepwise increase in the chance of survival by week of gestation has been shown in populations defined by place of birth, ${ }^{7}$ by neonatal intensive care nursery, ${ }^{89}$ and place of residence at birth. ${ }^{10}$ It is unclear whether there is a similar but inverse gradient in the disability rate among survivors by week of gestation-that is, an increase in the rate of disability by decreasing week of gestation. If there is such a gradient, this would need to be taken into account by both clinicians and parents, who need to make decisions about providing care for extremely immature babies.
The Oxford Low Birth Weight Study was carried out to investigate whether such a gradient exists. We have ascertained the outcome of all the babies born between January 1984 and December 1986 at less than 29 weeks' gestational age delivered to mothers who were resident in the area covered by the Oxford Regional Health Authority-the counties of Berkshire, Buckinghamshire, Northamptonshire, and Oxfordshire. We report mortality among these babies and their functional abilities at the age of 4 years.

\section{Methods}

Babies who were born before 29 weeks' gestation in 1984,1985 , and 1986 to mothers who were resident in the Oxford region at the time of birth were identified from three sources. Firstly, a telephone call was made once a week throughout the three year enrolment period to each of the 10 neonatal units in the region and information on all eligible babies was obtained. Secondly, copies of all death certificates issued for children who died under the age of 5 years were obtained from each district health authority for the same three year period. Finally, using birth notifications, the regional computer unit identified babies who had been born outside the region to mothers who were normally resident in the region.

Gestational age was estimated as the number of completed weeks from the last menstrual period. This was compared with the assessment of gestational age on ultrasonography (if possible on a scan performed before 20 weeks). The scan assessment was preferred only if it estimated a gestational age differing by more than 14 days from the estimate based on mothers' dates.

Babies who survived to be discharged were entered, with parents' consent, into a developmental screening programme carried out by health visitors. The children were seen by the health visitor at the age of 8 months, 18 months, and 3 years. As each child approached the age of 4 years the parents were sent a letter asking permission for their child to be visited at home by a paediatrician for a neurodevelopmental assessment.

This assessment included the Griffiths mental developmental scales, ${ }^{11}$ the test of motor impairment, ${ }^{12}$ the Egan bus puzzle test ${ }^{13}$ as an assessment of comprehension of speech and expressive ability, a neurological assessment, and measurement of weight, height, and head circumference. In addition parents were asked, from a questionnaire, about readmissions to hospital, intercurrent illnesses, family circumstances, and any problems the child had including specific questions on sleep and behavioural disturbances; this information is not reported in this paper.

At the end of the assessment the children were allocated to one of five categories based on the estimated level of impairment and functional disability. 
(1) Within normal limits in all respects; children functioning appropriately for age.

(2) Impairment present but no disability; for example, children with changes in muscle tone but without functional loss, or low scores on single test items.

(3) Impairment with mild disability; for example, children with low scores or poor performance in one or more fields of development who will possibly need additional help at school.

(4) Impairment with moderate disability; for example, children with overall low scores (more than 2 SD below the mean score) or motor deficit with some limitation of activity. It was considered that these children would need additional help in these areas with special provision at school.

(5) Impairment with severe disability, to include children with cerebral palsy with severe limitation of function, total loss of vision, sensorineural deafness, or overall developmental delay (developmental quotient $<70$ ).

We used a similar scoring system in a previous study. ${ }^{14}$ On rescoring at the completion of the study, blind to the original allocation, $96 \%$ of the children were assigned to the same group. When changes were made they tended to be between groups 2 and 3 and between groups 4 and 5 . This suggested that the threshold between groups 3 and 4 marked a clear boundary of functional severity. It is possible that some children who were allocated to group 2 may fall within the range of normal function and development and in this paper they are considered together with children in group 1. We recognise, however, that some children with mild neurological signs (like those seen in children in group 2) may manifest later learning difficulties. ${ }^{15}$

The assessments were carried out as near to the age of 4 years as possible with no correction for gestational age. Although the paediatrician knew all the children had been born very preterm, she was not aware of the exact gestational age, birth weight, or neonatal history before the assessment, and she had not been involved in their care in the neonatal period.

After the assessment, a brief summary of the findings was sent to the child's general practitioner and health visitor and, when requested, a copy of the summary letter was sent to the parents. Approval for the study was given by all eight district research ethics committees in the region.

Significance for trends in proportion was tested by the $\chi^{2}$ test for trend. Confidence intervals were calculated using the program CIA. ${ }^{16}$

TABLE I-Number (percentage) of babies by week of gestational age at birth

\begin{tabular}{lcccccc}
\hline & \multicolumn{7}{c}{ Gestational age at birth (weeks) } \\
\cline { 2 - 7 } & $\leqslant 24$ & 25 & 26 & 27 & 28 & Total \\
\hline Born alive & 60 & 45 & 66 & 69 & 102 & 342 \\
Alive at 24 hours & $14(23)$ & $25(56)$ & $45(68)$ & $60(87)$ & $98(96)$ & $242(71)$ \\
Alive at 1 week & $8(13)$ & $15(33)$ & $37(56)$ & $52(75)$ & $87(85)$ & $199(58)$ \\
Alive at 28 days & $7(12)$ & $14(31)$ & $35(53)$ & $44(64)$ & $84(82)$ & $184(54)$ \\
Discharged home from nursery & $5(8)$ & $10(22)$ & $32(49)$ & $43(62)$ & $80(78)$ & $170(50)$ \\
Alive at age of 4 years & $5(8)$ & $9(20)$ & $31(47)$ & $40(58)$ & $79(78)$ & $164(48)$ \\
\hline
\end{tabular}

TABLE $\mathrm{I}-$ Functional ability of children at age 4 years

\begin{tabular}{|c|c|c|c|c|c|c|}
\hline & \multicolumn{6}{|c|}{ Gestational age at birth (weeks) } \\
\hline & $\leqslant 24$ & 25 & 26 & 27 & 28 & Total \\
\hline Number of children alive ${ }^{\star}$ & 5 & 9 & 31 & 40 & 79 & 164 \\
\hline Group 1 & 1 & 0 & 3 & 5 & 6 & 15 \\
\hline Group 2 & 0 & 0 & 7 & 6 & 26 & 39 \\
\hline Group 3 & 0 & 3 & 6 & 15 & 20 & 44 \\
\hline Group 4 & 1 & 2 & 6 & 2 & 9 & 20 \\
\hline Group 5 & 3 & 4 & 6 & 11 & 11 & 35 \\
\hline Number of children assessed & 5 & 9 & 28 & 39 & 72 & 153 \\
\hline$\%$ Of survivors assessed & 100 & 100 & $90 \cdot 3$ & $97 \cdot 5$ & $91 \cdot 1$ & $93 \cdot 3$ \\
\hline
\end{tabular}

${ }^{\star}$ Definitions of groups $1-5$ are in the text.

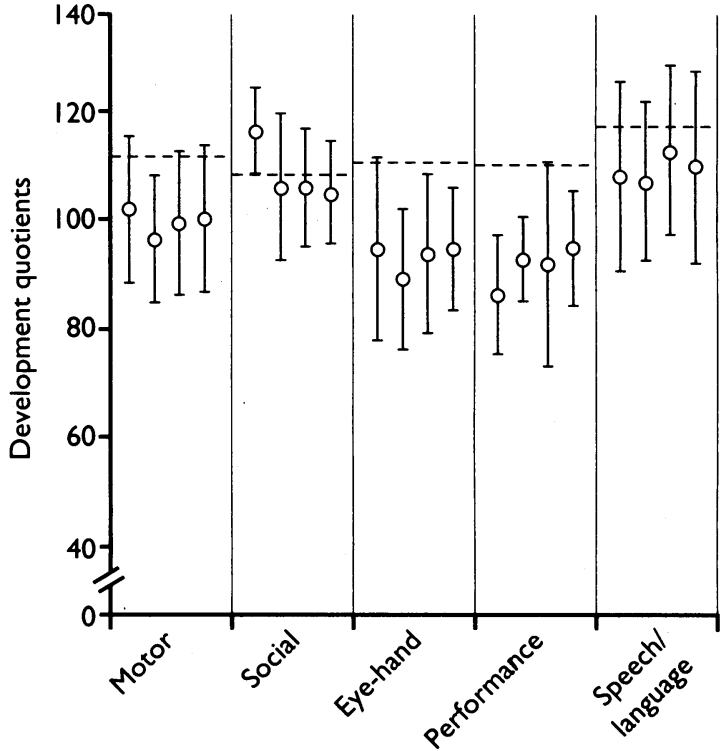

Score at $₹ 25-26-27-28$ weeks' gestational age for each subscale

FIG 2-Griffiths mental development scales: subscale quotients by week of gestational age at birth. Bars show $1 S D$; dotted line indicates population mean

\section{Results}

The total number of babies born alive during the three years of study was 98082 . Of these, 342 babies were born before 29 weeks of gestation $(3 \cdot 5 / 1000$ births); $277(81 \%)$ were singletons and $65(19 \%)$ were from multiple pregnancies. The proportion of babies who were alive at 24 hours, at 1 week, and at 28 days of age increased with each additional week of gestation at birth (table I) ( $\chi^{2}$ for trend in proportions $p<0.0001$ in each case). Half of the babies (170/342) survived to be discharged from the nursery. Of the 170 babies who were discharged home, six died before the age of 4 years: three with sudden infant death syndrome, two with progressive degenerative brain disorders, and one (with severe neuromotor impairment) after pneumonia.

At the age of 4 years, $153(93 \%)$ of the 164 children who were still alive were assessed; all 14 children who were born before 26 weeks of gestation were seen (table II). Of the 11 children not seen, five had gone abroad, the parents refused assessment in three, and a further three could not be traced.

When allocated to one of the five groups of functional ability, $35 \%$ (54) of the children were within normal limits (groups 1 and 2) at the age of 4 years, $29 \%$ (44) had an identifiable impairment with mild disability (group 3), 13\% (20) had a moderate disability (group 4), and 23\% (35) were severely disabled (group 5). Figure 1 shows the increasing risk of moderate to severe impairment and disability with decreasing gestational age at birth $\left(\chi^{2}\right.$ for trend in proportions $\mathrm{p}<0.003)$. The characteristics of the children in group 5-the most severely disabled-are shown in table III.

There is a further concern that children who are not severely or moderately disabled at the age of 4 years may nevertheless have mild impairments, particularly in the motor and visuoperceptive areas, which may be markers of later learning problems at school. ${ }^{15} \mathrm{We}$ looked for evidence of such impairment by measuring the mean Griffiths subscale scores for the children who were allocated to group 1,2 , or 3 in the overall functional scale. The Griffiths scores tended to fall below the population mean for each of the subscales (as estimated in a previous study of normal 4 year old children $^{14}$ ). There was no association, however, between mean subscale scores and gestational age at birth (fig 2). 
TABLE III-Characteristics of children with functional ability in group 5

\begin{tabular}{lc}
\hline & $\begin{array}{c}\text { No of children } \\
(\mathrm{n}=35)\end{array}$ \\
\hline Single system involved: & \\
$\quad$ Neuromotor (cerebral palsy) & 9 \\
Vision (blind) & 6 \\
Hearing (bilateral aids) & 3 \\
$\quad$ Intellectual (DQ < 70) & 7 \\
Multiple systems involved: & 3 \\
$\quad$ Cerebral palsy+blindness & 5 \\
Cerebral palsy+intellectual deficit & 2 \\
\hline Cerebral palsy+deafness & \\
\hline
\end{tabular}

TABLE IV-Status of babies in cohort at age 4 years

\begin{tabular}{lrrrr}
\hline & \multicolumn{4}{c}{ Gestational age in weeks } \\
\cline { 2 - 5 } Status & $\leqslant 25$ & 26 & 27 & 28 \\
\hline Died & 91 & 35 & 29 & 23 \\
Moderately or severely disabled & 10 & 12 & 13 & 20 \\
Impaired & 3 & 6 & 15 & 20 \\
Normal & 1 & 10 & 11 & 32 \\
Not seen & 0 & 3 & 1 & 7 \\
\hline Total & 105 & 66 & 69 & 102 \\
\hline
\end{tabular}

A summary of the overall outcome, including mortality and morbidity, by week of gestation is shown in table IV. The rate of "intact survival" increased with increasing gestational age ( $\chi^{2}$ for trend in proportions $\mathrm{p}<0.001$ ).

\section{Discussion}

Early in the 1980 s, reports of the later health of very preterm survivors tended to be gloomy and doubts were cast on the wisdom of resuscitating very immature babies. ${ }^{17}$ As the decade progressed, however, it became clear that babies born as early as $23-24$ weeks could survive without major disability, and more optimistic reports appeared..$^{18-20}$ Many of these estimates of risk of later impairment and disability were based on very small numbers of survivors and were often confined to babies who had been born in or nursed in a single neonatal unit.

In the late $1980 \mathrm{~s}$, reports based on populations defined by residence at birth ${ }^{2122}$ suggested that, in contrast to the clear evidence of decreasing risk of disability with increasing gestational age above 28 weeks, ${ }^{102}$ there was a "plateau" in the disability rate below 28 weeks. These observations were again based on a very small number of surviving babies in the lowest gestational age groups. Our study was an attempt to amass larger numbers, being based on a region with a population of 2.6 million, and we were able to show that for babies born to mothers resident in the area in the mid-1980s the rate of severe disability among survivors increased with decreasing gestational age. The occurrence of preterm birth was still sufficiently rare, however, for the numbers of surviving babies in the 24-25 week gestational age range in our study to be small. It would seem that pooling regional data is necessary to give reliable estimates of the risk of impairment and disability among the most immature babies.

Since the birth years of this study, mortality has continued to fall, and therefore even if the rate of disability remains constant the number of disabled survivors will increase. ${ }^{24}$ Balanced against this, of course, is the likelihood that there will also be an increase in the number of normal healthy children who, in the $1980 \mathrm{~s}$, would have died. An estimate of the size of such gains and the changing balance of disability and health year by year can be estimated only by systematic ascertainment of the later health and wellbeing of large numbers of very preterm babies.

This type of information is not currently available through routine systems and is difficult to obtain and interpret from other sources for a number of reasons. ${ }^{125}$ In particular there are differences in the way populations are defined and in the way children are described. These problems are illustrated by our attempts to compare the outcome of four geographically defined populations of babies born before 28 weeks of gestation in the 1980 s (table V). Mortality was similar in the four populations, with a third of the babies surviving to discharge. Disability rates differed widely, however, and although it is possible that this is related to differences in patterns of care, it is as likely that these apparent differences merely reflect differences in the way that the children are described and severe disability is defined. A further issue in the interpretation of the differences in impairment and disability rate is that health status and functional ability at the age of 4 years reflects not only pattern of care but also environmental and other influences during later infancy and childhood.

TABLE V-Comparison of mortality and disability in four geographically defined populations of babies born before 28 weeks of gestation. Values in parentheses are numbers of babies

\begin{tabular}{|c|c|c|c|c|}
\hline $\begin{array}{l}\text { Area of residence } \\
\text { at birth }\end{array}$ & $\begin{array}{l}\text { Years of } \\
\text { birth }\end{array}$ & $\begin{array}{c}\text { Number } \\
\text { of } \\
\text { liveborn } \\
\text { babies }\end{array}$ & $\begin{array}{c}\text { Survival } \\
\text { rate/ } \\
1000 \text { live } \\
\text { births }\end{array}$ & 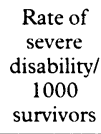 \\
\hline Northern region ${ }^{10}$ & 1983 & 98 & $327(32)$ & $219(7)$ \\
\hline Netherlands ${ }^{22}$ & 1983 & 255 & $349(89)$ & 191 (17) \\
\hline Scotland ${ }^{26}$ & 1984 & 210 & $290(61)$ & $131(8)$ \\
\hline Oxford region & $1984-6$ & 240 & $354(85)$ & $282(24)$ \\
\hline
\end{tabular}

A difficulty that arises when interpreting morbidity information as part of the evaluation of neonatal intensive care is the time lag between birth and the time when estimates of impairment and disability are made. This leads to the inevitable claim that follow up data are always out of date as new obstetric and neonatal interventions and approaches have been adopted since the birth year of the cohort under study. An example of this is the recent introduction of exogenous surfactant therapy.

Perhaps the best approach would be to collect a small core set of information on each child within agreed birth weight or gestational age bands at the age of 18 months or 2 years. This could include information on the presence of severe neuromotor impairment, blindness, deafness, and severe global delay or other major organ involvement such as chronic lung disease or short bowel syndrome. Information of this sort, with clear definitions of diagnostic groups, and with standard descriptions of impairments and levels of function reported in a consistent way on populations described by geographic area at the time of birth, could be drawn from district based child health information systems, local registers of impairment, routine follow up clinic sources, and special surveys and studies.

Neonatal intensive care has been described as "perhaps the most successful of all medical technologies." ${ }^{27}$ In terms of improving the chance of survival this may well be so, but we now need to establish reliable information about the proportion of survivors who are disabled.

The authors gratefully acknowledge Rosemary King for her help in contacting neonatal nurseries, the paediatricians in the Oxford Region for permission to include their patients in the study, and particularly the parents of the children for their cooperation and interest in the project. The study was funded by Action Research.

1 Escobar GJ, Littenberg B, Petitti DB. Outcome among surviving very low birthweight infants: a meta-analysis. Arch Dis Child 1991;66:204-11.

2 Alberman E, Botting B. Trends in prevalence and survival of very low birthweight infants, England and Wales: 1983-7. Arch Dis Child 1991;66:
(1) 1304-8. 
3 Macfarlane A, Cole S, Johnson A, Botting B. Epidemiology of birth before 28 weeks of gestation. Br Med Bull 1988;44:861-93.

4 Pharoah POD, Cooke T, Cooke RWI, Rosenbloom L. Birthweight specific trends in cerebral palsy. Arch Dis Child 1990;65:602-6.

5 Stanley FJ, Watson L. Trends in perinatal mortality and cerebral palsy in Western Australia, 1967 to $1985 . B M 7$ 1992;304:1658-63.

6 Scottish Stillbirth and Neonatal Death Repors; 1988 and 1989. Edinburgh: Information and Statistics Division, Scotland, 1991

7 Yu VYH, Loke HL, Bajuk B, Szymonowicz W, Orgill AA, Astbury J. Prognosis for infants born at 23 to 28 weeks' gestation. $B M$ T $^{2} 1986 ; 293$ : $1200-3$.

8 Verloove-Vanhorick SP, Verwey RA, Brand R, Bennebroek Gravenhorst Keirse MJNC, Ruys JH. Neonatal mortality risk in relation to gestationa age and birthweight. Lancet 1986;ii:55-7.

9 Heinonen K, Hakulinen A, Jokela V. Survival of the smallest. Time trends and determinants of mortality in a very preterm population during the 1980 s. Lancet 1988;ii:204-6.

10 Wariyar U, Richmond S, Hey E. Pregnancy outcome at 24-31 weeks' gestation: neonatal survivors. Arch Dis Child 1989;64:678-86.

11 Griffiths R. The abilities of young children. High Wycombe: Association for research in infant and child development, 1970.

12 Henderson S, Sugden DA. Movement assessment battery for children. London: Psychological Corporation, 1992.

13 Egan DF, Brown R. Developmental assessment: 18 months to $4^{12}$ years. The bus puzzle test. Child Care Health and Development 1984;10:163-79.

14 Dennis J, Johnson A, Mutch L, Yudkin P, Johnson P. Acidbase status at birth and neurodevelopmental outcome at four and one-half years. Am $\mathcal{F}$ Obstet Gynecol 1989;161:213-20.

15 Marlow N, Roberts BL, Cooke RWI. Motor skills in extremely low birthweight children at the age of 6 years. Arch Dis Child 1989;64:839-47.

16 Gardner MJ, Gardner SB, Winter PD. Confidence interval analysis. Version 1.1. London: BMJ, 1991
17 Schechner S. For the 1980s: how small is too small? Clinics in Perinatology 1980;7:135-43.

18 Cooke RWI. Outcome and costs of care for the very immature infants. $\mathrm{Br} \mathrm{Med}$ Bull 1988;44:1133-51.

19 Saigal S, Rosenbaum P, Hattersley B, Milner R. Decreased disability rate among 3 year old survivors weighing 501 to 1000 grams at birth and born to residents of a geographically defined region from 1981 to 1984 compared with 1977 to 1980 . I Pediatr 1989;114:839-46.

20 Victorian Infant Collaborative Study Group. Improvement of outcome for infants of birth weight under $1000 \mathrm{~g}$. Arch Dis Child 1991;66:765-9.

21 Saigal S, Rosenbaum P, Stoskopf B, Sinclair JC. Outcome in infants 501 to $1000 \mathrm{gm}$ birth weight delivered to residents of the McMaster health region. f Pediatr 1984;105:969-76.

22 Van-Zeben-van der Aa TM, Verloove-Vanhorick SP, Brand R, Ruys JH. Morbidity of very low birthweight infants at corrected age of two years in geographically defined population. Report from project on preterm and small for gestational age infants in the Netherlands. Lancet 1989;i:253-5.

23 Powell TG, Pharoah POD, Cooke RWI. Survival and morbidity in a geographically defined population of low birthweight infants. Lancet 1986;i:539-44.

24 Chalmers I, Mutch L. Are current trends in perinatal practice associated with an increase or a decrease in handicapping conditions? Lancet 1981 ;i:1415.

25 Aylward GP, Pfeiffer SI, Wright A, Verhulst SJ. Outcome studies of low birth weight infants published in the last decade: a meta analysis. $\mathcal{f}$ Pediat 1989;115:515-20.

26 Scottish Low Birthweight Study: I. Survival, growth, neuromotor and sensor impairment. Arch Dis Child 1992;67:675-81.

27 Paneth N. Neonatal care and patterns of disability in the community. Clinics of Developmental Medicine 1993;123/124:232-4

(Accepted 5 May 1993)

\title{
Can paternal preconceptional radiation account for the increase of leukaemia and non-Hodgkin's lymphoma in Seascale?
}

\author{
L J Kinlen
}

\begin{abstract}
Objective-To determine if the excess of leukaemia and non-Hodgkin's lymphoma in Seascale is restricted to those born in the parish and whether it might be explained by the postulated relation with paternal preconceptional radiation.
\end{abstract}

Design-Comparison, separately for those born in the parish and those born elsewhere, of the numbers of these malignancies observed in Seascale with those expected on the basis of reference rates for England and Wales. Details of paternal radiation levels were sought for each case.

Setting-The parish of Seascale in west Cumbria.

Subjects-Residents of Seascale below age 25 years in the years 1951-91.

Main outcome measures-The observed and expected numbers of cases of leukaemia and nonHodgkin's lymphoma within Seascale among those born there and among those born elsewhere. Also, the levels of any paternal preconceptional radiation associated with each case.

Results-A significant excess of leukaemia and non-Hodgkin's lymphoma at ages 0-24 was found in Seascale in those who were born there (ratio of observed to expected cases 8.6 and 20.2 respectively; $p<0 \cdot 01)$. This also applied to those not born there $(7.2$ and $16.5 ; p<0.01)$, a group often regarded as not showing an excess. The estimates were then conservatively recalculated so as to overestimate the risks among those born in Seascale and underestimate them among those born elsewhere. On this basis the six cases in those born in Seascale compare with 0.38 expected $(15.8 ; p<0.001)$, of which two were associated with paternal preconceptional lifetime levels of $100 \mathrm{mSv}$ or greater and three others with levels of $90-99 \mathrm{mSv}$. Among those born elsewhere, there were five cases (expected 0.74 ; ratio $6.7, p<0.01$ ), of which only one was associated with a high level of such radiation.

Conclusions-Paternal preconceptional radiation cannot be the sole cause of the excess in Seascale since it will not explain the excess among those born outside Seascale. It follows that, unless two causes are to be postulated, any single cause must be a factor other than paternal preconceptional radiation. On this basis, the association found among those born there, if not partly due to chance, may reflect an indirect relation with the true cause. The recent hypothesis about such paternal radiation has originated in a subgroup of the excess cases that have aroused concern.

\section{Introduction}

An increased incidence of leukaemia and nonHodgkin's lymphoma among young people in Seascale near the nuclear site of Sellafield in west Cumbria has been the subject of much study. Recent work has further strengthened the evidence of an excess, indicating its magnitude as well as its persistence into a recent period. ${ }^{1}$ The suggested explanation for this excess attracting most attention is that concerning paternal preconceptional exposure to relatively high levels of radiation. ${ }^{2}$ This association with leukaemia, which emerged from a study restricted to young people born in west Cumbria, is postulated to be causal and also to explain the excess in Seascale. ${ }^{2}$ In fact, the relevant paternal exposure details have been reported only for those children born in Seascale-because no excess was considered to be present in young people who were born elsewhere. ${ }^{34}$ However, this view has been questioned, and the need for paternal details in cases of these malignancies among those born outside Seascale has been emphasised. ${ }^{5}$ These aspects are examined here.

\section{Methods}

\section{LEUKAEMIA AND NON-HODGKIN'S LYMPHOMA}

Cases of leukaemia and non-Hodgkin's lymphoma recurring below age 25 in Seascale from 1951 to 1991 were identified. The particulars of cases up to 1983 which are listed in the report of the Black Advisory Group $^{6}$ have been supplemented by details obtained 